\title{
Research and Analysis of a Persistent Heavy Pollution Event in Ningbo, China
}

\author{
Jianmin Guo',2, Yuguang Guo², Chen Zhou ${ }^{3}$ \\ ${ }^{1}$ Ningbo Meteorological Service Center, Ningbo, China \\ ${ }^{2}$ Ningbo Meteorological Observatory, Ningbo, China \\ ${ }^{3}$ Ningbo Meteorological Safety Technology Center, Ningbo, China \\ Email: comhost@163.com
}

How to cite this paper: Guo, J. M., Guo, Y. G., \& Zhou, C. (2019). Research and Analysis of a Persistent Heavy Pollution Event in Ningbo, China. Journal of Geoscience and Environment Protection, 7, 60-71. https://doi.org/10.4236/gep.2019.710005

Received: July 26, 2019

Accepted: October 22, 2019

Published: October 25, 2019

Copyright (c) 2019 by author(s) and Scientific Research Publishing Inc. This work is licensed under the Creative Commons Attribution International License (CC BY 4.0).

http://creativecommons.org/licenses/by/4.0/

(c) (i) Open Access

\begin{abstract}
From 7 to 12 January 2015, there was a rare persistent severe pollution event in Ningbo. Based on the data from routine weather observation, automatic weather station in Zhejiang Province and urban pollutant monitoring in Ningbo City, by using the particle backward trajectory analysis of NOAA HYSPLIT4 model, the diagnosis and analysis of the pollution development and dissipation process were carried out. The results show that: 1) Pollutants carried by cold air are main reason for pollution in the first stage of the pollution process. The transition from near-surface northwest wind to north-northeast wind is the key to air improvement; 2) Favorable atmospheric circulation is the important reason for the long-term persistence of pollution. The long-term control of high-pressure center and low-level inversion between the two cold air effects make the boundary layer particularly stable, while the low horizontal wind speed is beneficial to polluting particles. With the continuous accumulation, the contaminated particles can not effectively diffuse either vertically or horizontally; 3) In the late period of January 11, the supplement of weak cold air in the East Road made the air quality index (AQI) climb to about 300 again. The two advection conveyances of cold air to pollutant particles and the long-term stable maintenance of weather conditions conducive to the accumulation of pollutant particles are two important reasons for this rare and sustained heavy pollution event.
\end{abstract}

\section{Keywords}

Heavy Pollution, Air Quality Index (AQI), Backward Trajectory

\section{Introduction}

In recent years, with the rapid increase of urbanization level, the emissions of 
motor vehicles, fossil fuel combustion, industrial waste gas, etc. have also been rising, and air pollution has occurred frequently in various places (Cao et al., 2018; Li et al., 2018; Yang et al., 2010; Jiao et al., 2016). Ningbo is the economic center of the south wing of the Yangtze River Delta. The economy has maintained a rapid development speed. The continuous increase of energy consumption and the continuous expansion of industrial scale have led to the emergence of a large number of gas pollutants. The atmospheric environment has become increasingly apparent. With the rapid development of the national economy, the living standards of residents have been continuously improved. The impact of quality on public health and quality of life is receiving increasing attention.

There are many works on air pollution. Numerous studies have shown that PM2.5, the main air pollutant, can be produced not only by local human or natural factors, but also under certain conditions, it can be transported from a distance to the local by atmospheric movement to study pollutants. Transmission characteristics, analysis of potential sources of pollutants, can provide an important basis for the government to carry out air pollution prevention and control (Liu et al., 2010; Wang et al., 2008).

In addition to local man-made and natural factors, pollutants in the air can also be transported from a long distance to the local or diffused to the local by atmospheric movement. The range of transport and diffusion is as small as several hundred meters, up to a few hundred meters. Regional, intercontinental and even global scales, so pay attention to the quality of a city's atmospheric environment, not only to consider the impact of the local area, but also consider the impact of the surrounding area (Yu et al., 2015; Zhu et al., 2007; Yao et al., 2017).

In the case of little change in the local pollutant discharge season, the air quality in Ningbo has a poor autumn and winter season and good seasonal characteristics in summer, which is not only related to the difficulty in spreading static and stable weather pollutants under the control of continental high pressure in autumn and winter, but also cold in winter. There are many reasons such as the influence of air and the source of external sources of pollution. Exogenous input air pollution caused by cold air carrying pollutants often occurs in autumn and winter, almost accompanied by every cold air intrusion, which has a great impact on air quality, often causing moderate to moderate pollution and living for the people great influence.

Studies have shown that the air quality of all moderate and above pollution levels in Ningbo is $100 \%$ in the autumn and winter seasons; the number of lightly polluted air days is $66.7 \%$ in the autumn and winter, and the air level is $50 \%$ in good days. The number of days in the air accounts for $10 \%$, and autumn and winter are the high incidence of moderate and above air pollution in Ningbo (Jiang et al., 2016).

Other studies have shown that strong cold advection flows intrude to the 
ground from the middle and upper levels,and wind speed increases resulting in favorable meteorological conditions for the diffusion of air pollutants. The cold air activities all correspond to the smallest values of AQI (Song et al., 2017). However, this is exactly the opposite of the experience of environmental forecasting in Ningbo. To understand the relationship between cold air and local pollution, trace the external source of air pollution, study the transmission characteristics of pollutants, and analyze the potential pollution sources of pollutants, which will help the time forecasting and early warning of air pollution. It provides an important basis for government pollutant discharge control and air pollution prevention and control work, and has practical guiding significance for the public to reasonably arrange life production and travel activities. It is also one of the environmental problems that need to be solved urgently in the process of sustainable development of Ningbo economy.

In the middle and early January of 2015, a serious pollution incident occurred in Ningbo City. From January 5 to 12, there were 123 hours of AQI reaching the pollution level. In order to study the cause of the outbreak of this pollution in Ningbo, the boundary layer of Ningbo area Meteorological elements is used for diagnostic analysis. The HYSPLIT4 model is used to analyze the trajectories of aerosol particles to deepen the understanding of the boundary layer circulation characteristics of contaminated particles for a long time, and to establish a conceptual model of particle trajectories to provide technical reference for air quality prediction.

\section{Materials and Methods}

The data used include the conventional weather maps from January 6-13, 2015, the GDAS (Global Data Assimilation System) data of the US NCEP, the monitoring data of the main pollutants of the eight monitoring points in the Zhejiang Province automatic weather station and Ningbo City (Ningbo Environmental Protection) provided by the Bureau, Beilun District Environmental Protection Building, Wanli College, Longsai Hospital, Sanjiang Middle School, Wanli International School, Qianhu Water Plant, Taikoo Primary School, and Municipal Environmental Monitoring Center [11]. In addition to the weather map and GDAS data, the other is hourly data, and the wind direction and wind speed are averaged at 10 minutes. The automatic weather station data comes from the Zhejiang Meteorological Information Center. This part of the data has been quality-controlled before it is put into storage, and there is no more processing when it is applied. The concentration of pollutants in Ningbo City is the average of the monitoring points of the eight national control stations, and the meteorological elements are represented by Zhangzhou Station (58562).

In this paper, the HYSPLIT-4 method is used to study the air pollutant transport path. The HYSPLIT4 mode is a computational mode of Euler and Lagrangian hybrids. The Lagrange method is used for the advection and diffusion, and the Euler method is used for the concentration calculation. This mode is often 
used in the meteorological industry and is suitable for trajectory calculation (forward and backward). The HYSPLIT-4 model is a comprehensive model system for feed point trajectory, diffusion and sedimentation analysis developed by the National Oceanic and Atmospheric Administration (NOAA). It uses the global reanalysis data of the National Environmental Prediction Center NCEP (GDA data) (latitude and longitude resolution) $0.5^{\circ} \times 0.5^{\circ}$, including basic information such as UV wind, humidity, temperature, etc.) is the diffusion mode of the Eulerian-Lagrangian hybrid type. The advection and diffusion calculations use the Lagrangian method, which is usually used to track the particles carried by the airflow or the direction of gas movement. Using the terrain $\delta$ coordinates, the horizontal grid is the same as the input meteorological field, and the vertical direction is divided into 28 layers, and the meteorological elements are linearly interpolated to each $\delta$ layer. This model has a relatively complete transport, diffusion and sedimentation model for processing multiple meteorological input fields, multiple physical processes and different types of pollutant discharge sources. It has been widely used in the study of atmospheric pollutant transport and diffusion (Weng et al., 2016; Yang et al., 2017; Wang et al., 2015; Wang, 2013; Hua, 2016; Draxler \& Hess, 1998).

\section{Cases of Live Analysis}

\subsection{Circulation Situation}

In the process, there are two cold airs with different paths and strengths affecting Ningbo City. Since January 4, 2015, strong cold air has moved eastward and southward from the Hetao area, which belongs to the middle road cold air. The $500 \mathrm{hPa}$ is mainly characterized by westerly wind and $700 \mathrm{hPa}$ high altitude. After the trough transited, it turned to the northwest wind. The ground temperature of the ground station was 10.2 degrees and the lowest was 3.2 degrees, reaching the cold wave standard. Figure 1 (a) and Figure 1(b) show the weather conditions at 20 o'clock on the $5^{\text {th }}$ and 8 o'clock on the $6^{\text {th }}$. It can be seen that on the $5^{\text {th }}$ night, the ground gradually turned from northerly wind to northerly wind, and cold air began to affect Ningbo. At the same time, the average AQI of the city climbed rapidly. At 8 o'clock on the $6^{\text {th }}$, it reached the highest value of 297. Since 08:00, weak precipitation began to appear in some areas of the city. The wind direction also gradually turned from the northwesterly wind at 08:00, and turned northerly at 10 o'clock. The air quality improved rapidly. At 13 o'clock, the AQI has dropped below 70. After that, the wind direction is reversed and the west is slightly swaying. However, the northerly wind is still dominant. On the morning of the $7^{\text {th }}$, the wind direction is northwesterly and the wind is strengthened. The concentration began to rise slowly and reached pollution again at 23:00 on the $7^{\text {th }}$. After a favorable circulation situation, the air pollution incident lasted for 107 hours, forming an extremely rare air pollution process in Ningbo.

From the $5^{\text {th }}$ to the $12^{\text {th }}, 850 \mathrm{hPa}$ has been dominated by high winds in the 


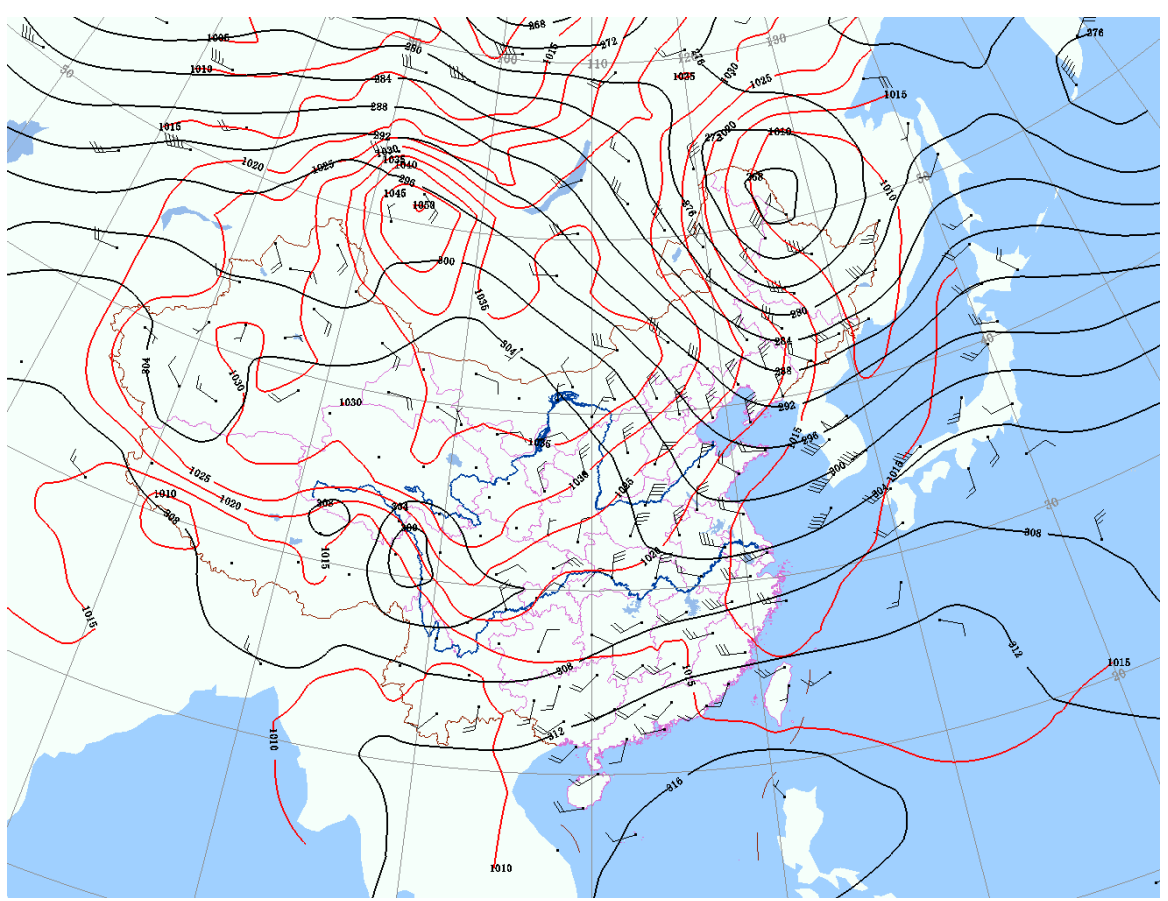

(a)

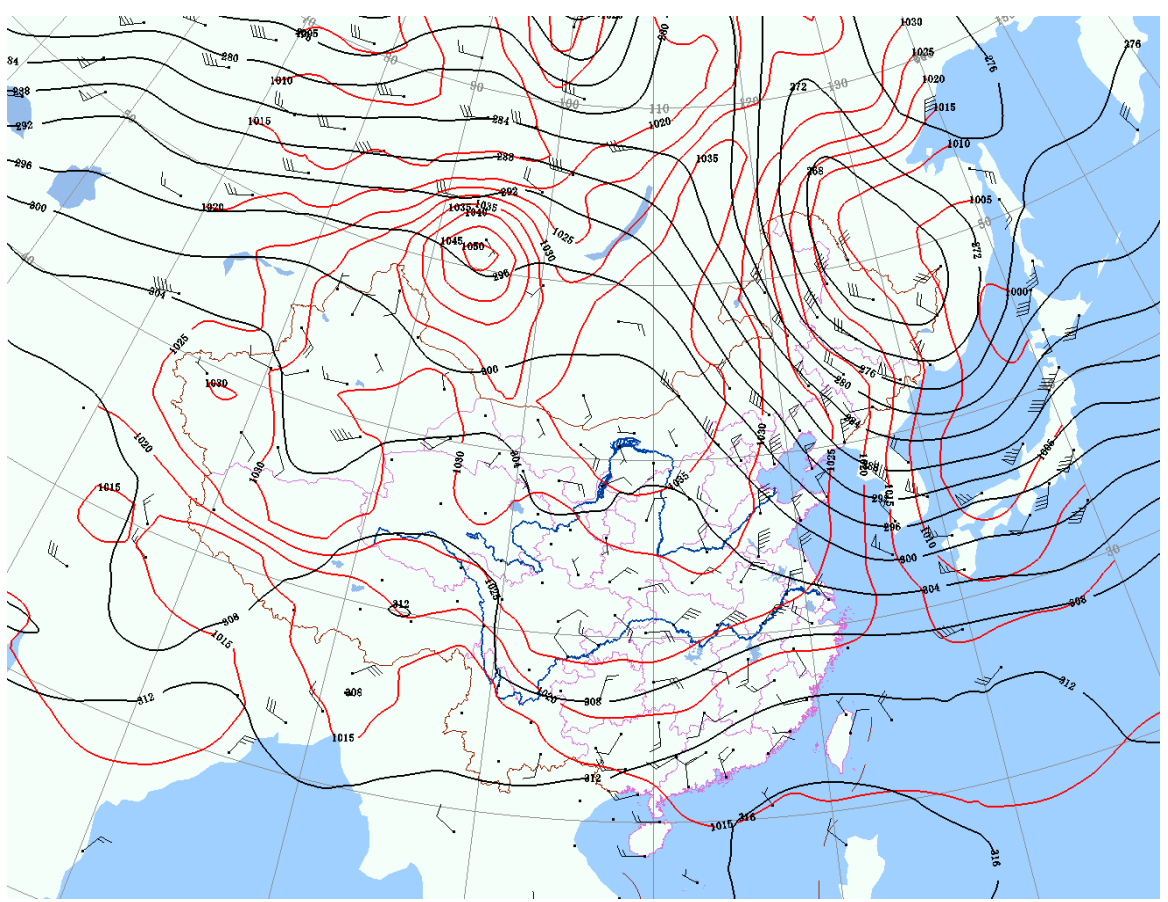

(b)

Figure 1. Sea level pressure field (hPa), $700 \mathrm{hPa}$ height field (dagpm) and $850 \mathrm{hPa}$ wind field (m/s) at 20:00 on January 5, 2015 (a) and 08:00 on January 6, 2015 (b) (The red contour is the sea level isobaric line, the black is the $700 \mathrm{hPa}$ contour line, and the feather is the $850 \mathrm{hPa}$ wind direction wind speed).

north. The intensity of cold air is very conducive to the long-distance transport of particulate matter. Before the $8^{\text {th }}$, the northerly wind was mainly on the ground, but the wind was not large. The wind speed on the sea was very large. It 
gradually turned into high-pressure control from the $8^{\text {th }}$. On the $11^{\text {th }}$, with the addition of weak cold air, the northerly wind on the ground increased again. The wind direction was mainly. The northeast wind belongs to the cold air of the east road.

\subsection{Pollution Overview}

The monitoring and analysis of six main pollutants (PM10, PM2.5, $\mathrm{NO}_{2}, \mathrm{SO}_{2}$, $\mathrm{CO}, \mathrm{O}_{3}$ ) in Ningbo City show that the average IAQI (Individual Air Quality Index) of $\mathrm{SO}_{2}, \mathrm{CO}$ and $\mathrm{O}_{3}$ is not from January 5 to 12,2015 . More than $40, \mathrm{NO}_{2}$ does not exceed 80, while PM10 and PM2.5 remain above 100 for a long time, maximum 285 , pollution time (IAQI $\geq 100)$ reaches $123(107+16)$ hours, the primary pollutants are PM2.5.

This extremely rare pollution process is mainly divided into two stages. The first stage lasts for 16 hours from $21: 00$ on the $5^{\text {th }}$ to the $12^{\text {th }}$ of the $6^{\text {th }}$, and the hourly AQI is 297 ( $8: 00$ on the $\left.6^{\text {th }}\right)$. After that, the air quality is rapidly improved. The second phase lasted for 107 hours from 23:00 on the $7^{\text {th }}$ to 9:00 on the $12^{\text {th }}$, and the maximum AQI was $286\left(0: 00\right.$ on the $\left.12^{\text {th }}\right)$. The primary pollutants in both stages are PM2.5, and the urban visibility shows a good negative correlation with AQI (mainly PM2.5) (Figure 2). When the AQI reaches 100 or more, the visibility is below $5 \mathrm{KM}$ for a long time. The minimum artificial visibility is only $600 \mathrm{~m}$.

\subsection{The First Stage Pollution Characteristics and Causes Analysis}

Before the first stage of pollution, the surface wind direction is dominated by southerly winds, and the AQI index is basically below 100. Especially on the morning of January 5 , as the temperature increases and the southerly wind speed increases, the boundary layer height increases, and the AQI value increases.

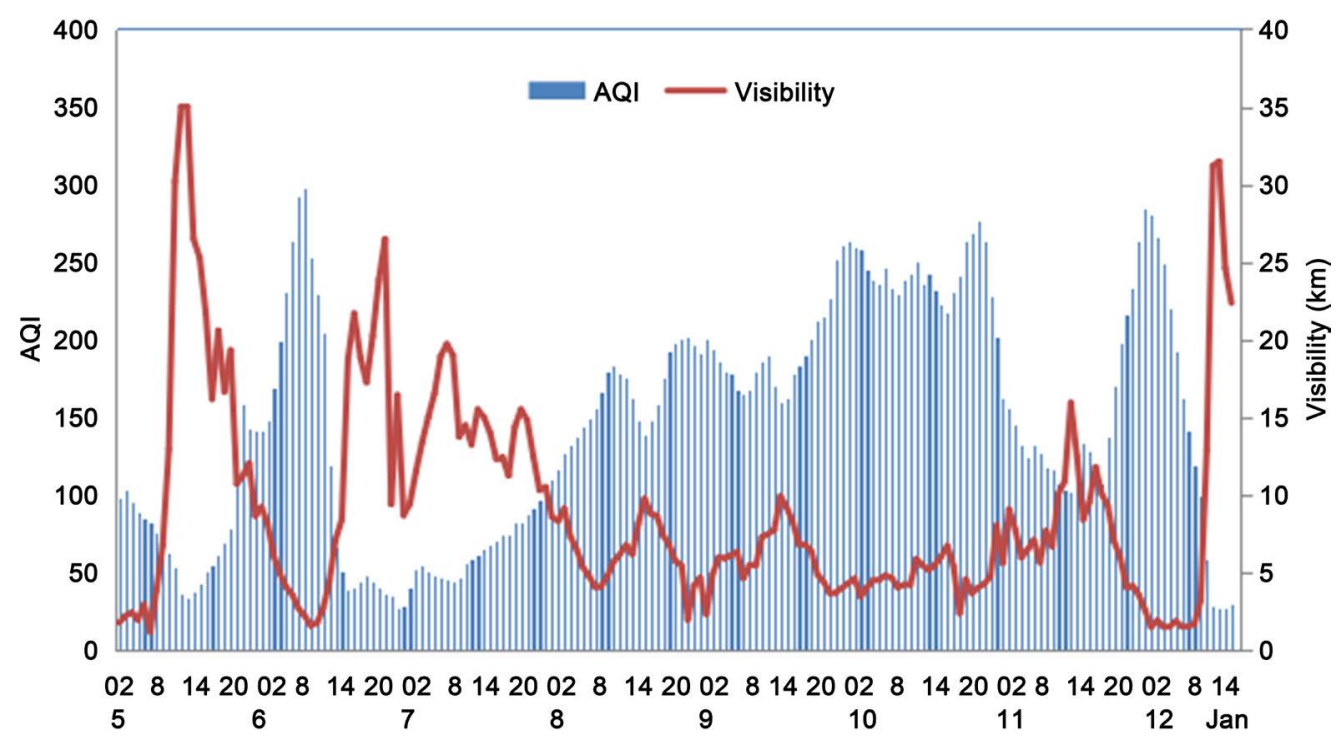

Figure 2. The hourly AQI and automatic visibility changes in Ningbo City from 02:00 to 2:00 on January 5, 2015 (abscissa: the upper row is time and the lower row is date). 
Constantly decreasing, the AQI index has been below 40 at 12-14, and gradually rebounded from the afternoon, showing the daily variation of AQI; since 21 o'clock, cold air began to affect, and the wind speed changed from southerly to northerly, and AQI also from 78 to 115 , after the northerly wind continued, AQI continued to climb, up to 297, pollution time lasted 16 hours, pollutants may come from the delivery of cold air; 8-10 am on the $6^{\text {th }}$, the city appeared light rain. At the same time, the wind direction gradually turned from the northwest wind. At 10 o'clock, it turned to the northerly wind. During the period, the AQI dropped rapidly. After 13 o'clock, the AQI of the northeast wind fell below 70, and then the wind swayed slightly westward, but still mainly northerly winds, the pollution phenomenon was suspended and continued to the next pollution outbreak. It can be seen that the pollution source mainly comes from the transportation of cold air. The end of pollution originates from the change of surface wind direction. After the northwest wind turns to northerly wind or northeast wind, the pollutant concentration decreases rapidly.

Taking the Ningbo Environmental Monitoring Center $\left(29.851^{\circ} \mathrm{N}, 121.524^{\circ} \mathrm{E}\right)$ as the starting point, the particle back trajectory analysis was performed on the $6^{\text {th }}$ of the $6^{\text {th }}$ (the AQI maximum time of the first pollution stage) using the HYSPILT4 mode of the US NOAA (Figure 3), the trajectory tracking period is based on the principle that the particle concentration is increasing, and the airflow backward trajectory of the first 12 and 24 hours at the initial time is calculated. The starting height of the model trajectory is $1000 \mathrm{~m}$, and the diffusion and mixing in the boundary layer of the mid-latitude area roughly corresponds to the middle of the boundary layer, so the top height of the model is set to $10,000 \mathrm{~m}$.

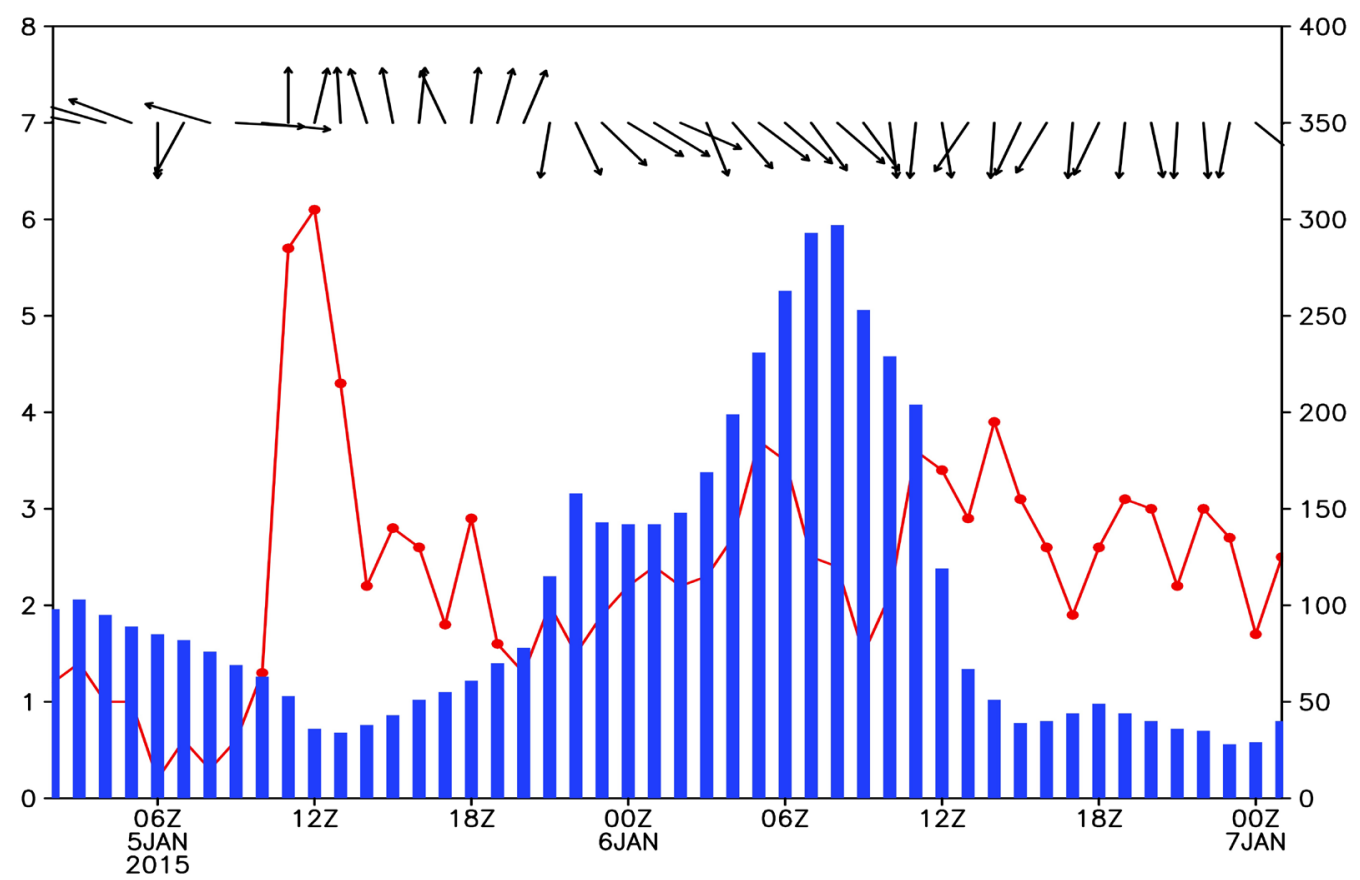

Figure 3. Wind direction (arrow), wind speed (red line, m/s), AQI (histogram) hourly change chart. 
The $12 \mathrm{~h}$ and $24 \mathrm{~h}$ particle back trajectories indicate (Figure 4). The near-surface particles below $100 \mathrm{~m}$ are mainly from the southern part of Ningbo, $300-500$ $\mathrm{KM}$ in the southwest of Ningbo, and the area of the source of the particles is below $100 \mathrm{~m}$. It is basically consistent with the surface wind direction, and the time when the pollutants soar is also the same as the time when the cold air arrives. It can be seen that this is a typical pollution process caused by cold air carrying pollutants. The advection of contaminated particles by cold air is the most important cause of air pollution. Since Ningbo North (Hangzhou Bay) and East (Donghai) are large areas of water, the sea air is relatively clean. After the wind direction turns from northwest to north and then northeast, the pollution level drops rapidly, and the pollution process is temporarily ended.

\subsection{The Second Stage Pollution Characteristics and Causes Analysis}

On the morning of the $7^{\text {th }}$, the wind turned north to northwest. At the same time, the wind strengthened, the concentration of particulate matter began to rise slowly, and reached pollution again at 23 o'clock. After that, it fluctuated until 9:00 on the $12^{\text {th }}$, during the evening from $9^{\text {th }}$ to $10^{\text {th }}$. More than ten hours of continuous heavy pollution and reached a stage high of 276 at $21: 00$ on the $10^{\text {th }}$, after which the AQI index remained at $100-200$, and again rose to above 200 at night on the $11^{\text {th }}$, up to $286\left(0: 00\right.$ on the $\left.12^{\text {th }}\right)$.

The thickness of the boundary layer is closely related to the atmospheric temperature. When the temperature rises, the boundary layer is well mixed and the thickness is increased, which is conducive to the vertical diffusion of pollutants.

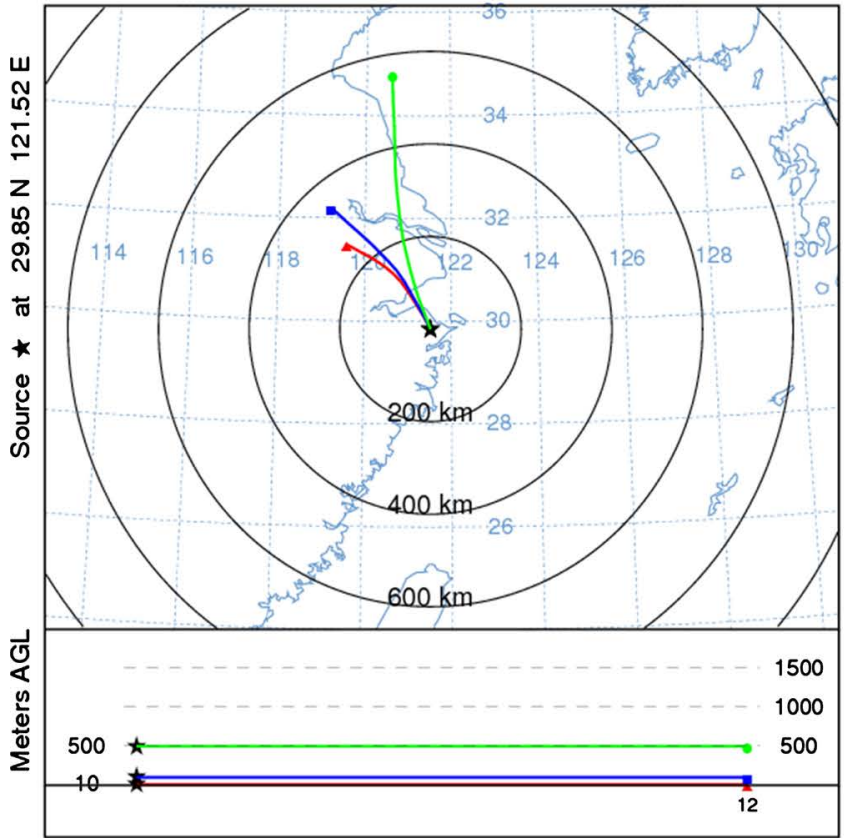

(a)

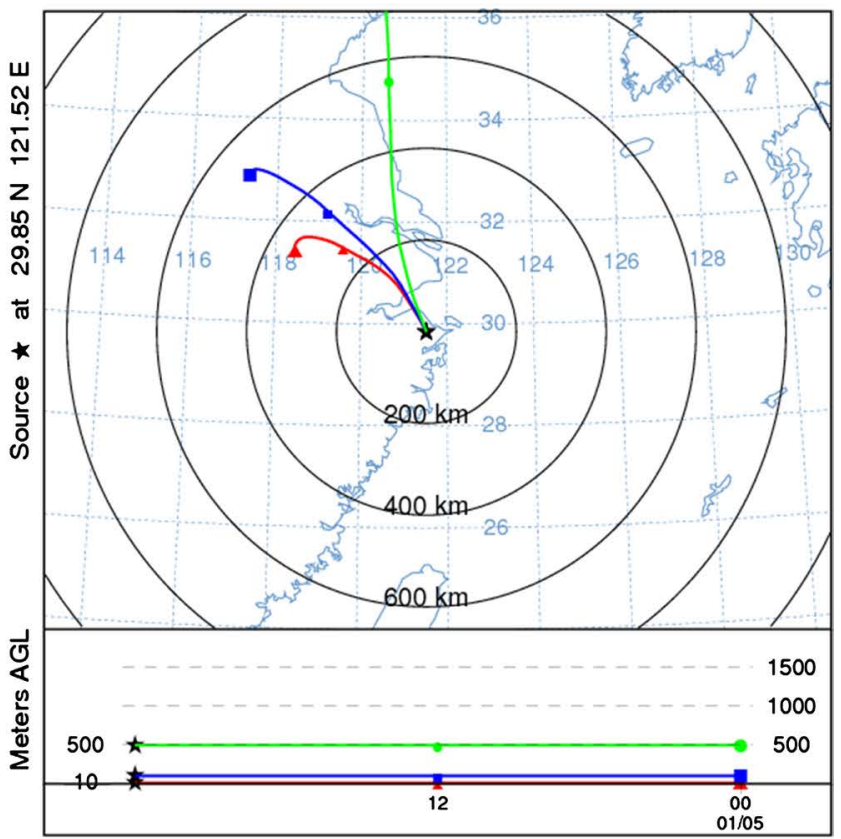

(b)

Figure 4. The initial time is the particle backward trajectory at 8 o'clock on January 6 ((a) $12 \mathrm{~h}$; (b) 24 h) (Red, blue, and green indicate altitudes of 10,100 , and $500 \mathrm{~m}$, respectively). 
Figure 5 shows a good negative correlation between AQI and temperature fluctuations in the second phase, with the concentration of pollution showing a daily variation above the upward trend.

The analysis of the circulation situation found that from 08:00 on the $8^{\text {th }}$ to 08:00 on the $11^{\text {th }}$, the Ningbo area has been near the high-pressure center (not shown), and the weak downdraft flow, according to the analysis of the convective sounding data of the initial field of the EC, from 08:00 to 9. At 08:00, the atmosphere near Ningbo is in a stable state, and the troposphere has an inverse temperature of about $925 \mathrm{hP}$ (about $800 \mathrm{~m}$ ) (shown in figure), forming a natural pollution cover, which limits the vertical diffusion of pollutants. From noon on the $7^{\text {th }}$ to the noon on the $12^{\text {th }}$ of the end of the pollution process, the wind in the urban area has been maintained at $1-2$, the wind direction is irregular, most of the time the wind speed is below $2 \mathrm{~m} / \mathrm{s}$ (Figure 6), small wind or calm wind. It is not conducive to the diffusion of pollutants, which is another important reason for the long-term pollution in the second stage.

The backward trajectory of the particles indicates (Figure 7). On the $7^{\text {th }}$, there are still pollutant particles in the direction of southern Jiangsu. In the early days of $8-11$, the pollution mainly originated from the accumulation of local polluted particles. From the late $11^{\text {th }}$ to the noon on the $12^{\text {th }}$, along with the East Road With the addition of cold air, AQI has soared to more than 200, up to 286 $\left(0: 00\right.$ on the $\left.12^{\text {th }}\right)$. The source of pollution is from the eastern coastal areas such as Jiangsu and even Shandong. During the period, the advection of pollutants by cold air is an important reason for AQI's new high.

\section{Conclusion}

Through the analysis of the rare persistent heavy pollution process in Ningbo City from January 5 to 12, 2015, it was found that carrying pollutants in cold air is the most important cause of pollution in the first stage of the pollution process.

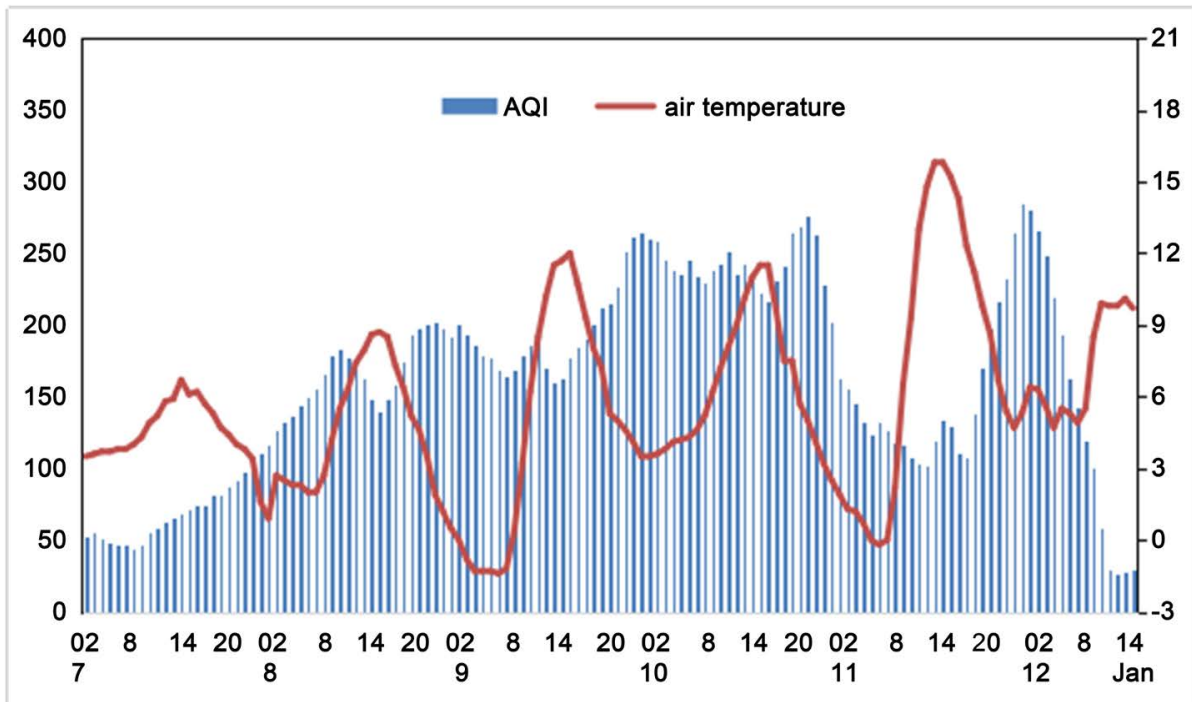

Figure 5. AQI and temperature change chart. 


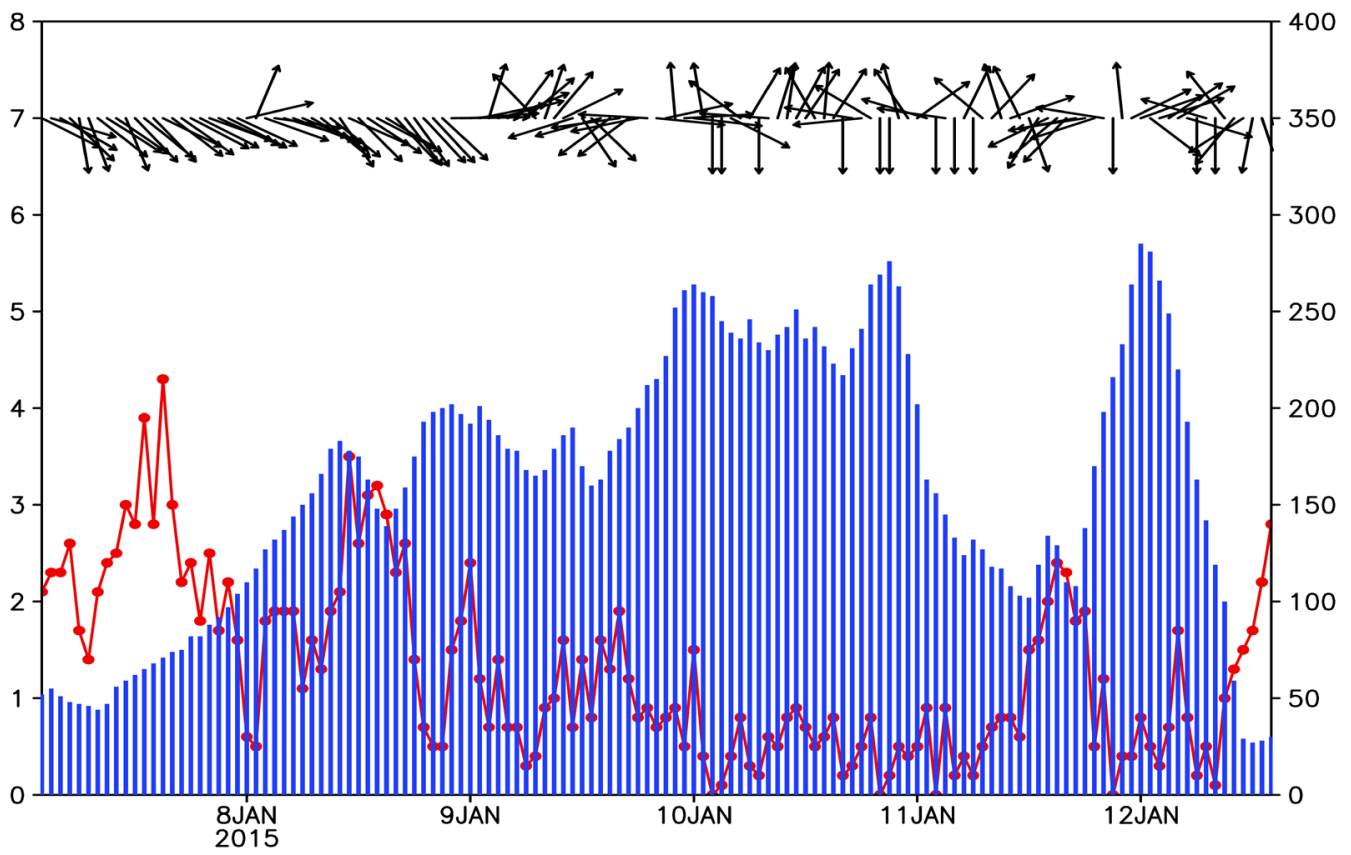

Figure 6. Wind direction (arrow), wind speed (red fold line, m/s), AQI (histogram) hourly change chart.
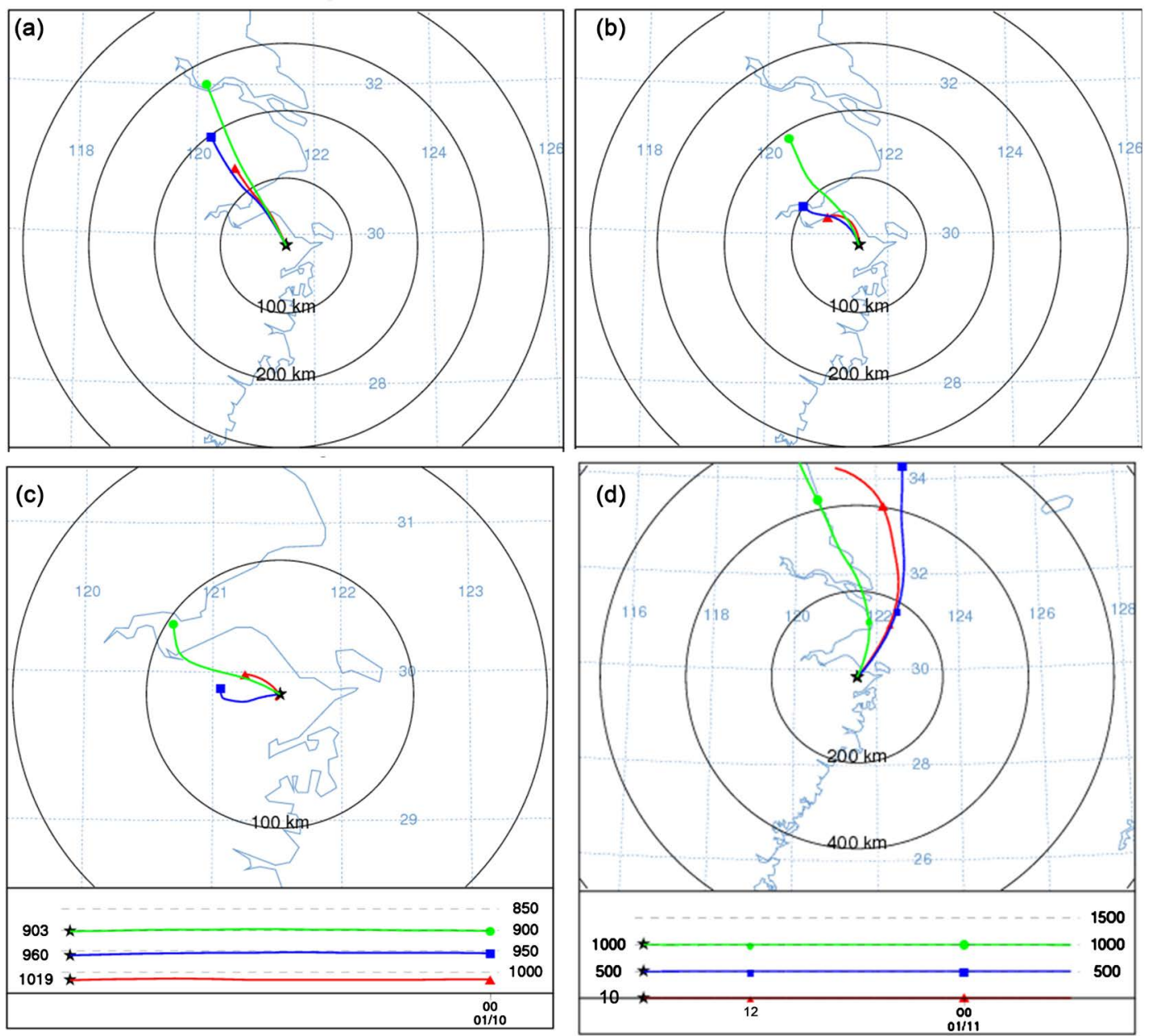

Figure 7. Backward trajectory ((a)-(c) 12 h, (d) 24 h). (a) August 20: (b) 9:20:00; (c) 10:20:00; (d) 12 pm 0:00. 
The shift from the northwest wind to the northeast wind is the key to air improvement.

The favorable atmospheric circulation situation is an important reason for the long-term pollution. Long-term high-pressure center control and low-level inversion make the boundary layer particularly stable, while the horizontal wind speed is low, which is conducive to the continuous accumulation of contaminated particles. It cannot be effectively diffused vertically or horizontally.

At the end of the $3^{\text {rd }}$ and $11^{\text {th }}$, the addition of weak cold air on the East Road caused AQI to climb to around 300 again. The two-time cold air's advection of contaminant particles and the long-term stable maintenance of the weather conditions that are conducive to the accumulation of contaminated particles are two important reasons for this rare persistent heavy pollution incident.

Industrial production processes are an important source of pollutant particles. Pollution prevention should start from the source and adopt a comprehensive management strategy. Governments and enterprises can improve existing dust removal technologies and equipment and strictly control dust pollution caused by industrial production during the advection input of pollutant particles and the weather conditions that are conducive to the accumulation of contaminated particles. At the same time, it is necessary to strengthen the dust management of construction sites and roads.

\section{Acknowledgements}

Project funding: Zhejiang Meteorological Science and Technology Project 2016QN04; Ningbo Science and Technology Project 2015C50056, Ningbo Meteorological Science Project NBQX2017005B.

\section{Conflicts of Interest}

The authors declare no conflicts of interest regarding the publication of this paper.

\section{References}

Cao, Y., Ma, J. H., Xu, J. M. et al. (2018). Analysis of a Typical Air Pollution Process in Shanghai. Journal of Meteorology and Environment, 32, 16-23.

Draxler, R. R., \& Hess, G. D. (1998). An Overview of HYSPLIT-4 Modeling System for Trajectories Dispersion and Deposition. Australian Meteorological Magazine, 47, 295-308.

Hua, C., Zhang, H. D., Zhang, B. H. I. et al. (2016). Analysis of Meteorological Transmission Conditions and Prediction Index of Heavy Pollution Weather in Beijing during the Winter Half of 2013-2014. Meteorology Monthly, 42, 314-321.

Jiang, W., Qian, Y. Z., Du, K. et al. (2016). Changes and Prediction of Ozone Concentration in the Near-Surface Layer of Ningbo City. Journal of Meteorology and Environment, 32, 53-59.

Jiao, S. M., Zhu, C. Y., Zhu, Y. Y. et al. (2016). Analysis of the Cause of a Rare Persistent Heavy Fog Process in Jiangsu Province. Acta Meteorologica Sinica, 74, 200-212.

Li, Y. Y., Yang, H. R., \& Wang, N. (2018). Analysis of the Causes of a Heavily Polluted 
Weather Process in Taiyuan City. Journal of Meteorology and Environment, 34, 11-18.

Liu, S. Z., An, J. L., Zhu, B. et al. (2010). The Effect of Long-Distance Transport on Atmospheric Pollution in Nanjing. Journal of Eco-Environment, 19, 2629-2635.

Song, G. Y., Jiang, J., Di, H., \& Chen, Y. G. (2017). Analysis of Air Pollution Control Measures and Meteorological Conditions in Hohhot during the APEC Meeting. Journal of Meteorology and Environment, 33, 63-69.

Wang, F. J., Zhong, Z. X., Wu, S. T. et al. (2015). Case Analysis of Input Dust Pollution in Wuhan City in May 2014. Journal of Peking University (Natural Science), 51, 1132-1140.

Wang, W. (2013). Using Trajectory Model to Study the Source of Air Pollution in Shanghai. Environmental Science Research, 26, 357-363.

Wang, Y., Chai, F. H., Liu, H. F. et al. (2008). Characteristics of Horizontal Pollutant Transport Field in the Yangtze River Delta. Environmental Sciences, 21, 22-29.

Weng, Z. M., Li, L. P., Yang, W. Y. et al. (2016). Backward Airflow Trajectories and Circulation Features of Different Deuterium Processes in Zhejiang Province in Winter. Meteorology Monthly, 42, 183-191.

Yang, H., Bai, Y. Q., Liu, L. et al. (2017). Research on Air Transport Channel of Air Pollution Process in Henan Based on Trajectory. Journal of Meteorology and Environment, 33, 29-39.

Yang, S. Y., Zhao, X. Y., \& Liu, N. W. (2010). Analysis of the Cause of a Heavily Polluted Weather Process in Beijing in Autumn. Journal of Meteorology and Environment, 26, 13-16.

Yao, R. S., Tu, X. P., Zhang, X. W. et al. (2017). Analysis of the Causes of a Rare Persistent Heavy Pollution Incident in Ningbo. Acta Meteorologica Sinica, 75, 342-355.

Yu, K. A., Xu, H. H., Huang, X. X. et al. (2015). Analysis of Air Pollution Change Characteristics and Pollutant Backward Trajectory in Ningbo in Autumn and Winter. Zhejiang Meteorology, 36, 27-31.

Zhu, L. Y., Cai, J. Z., Zhang, M. G. et al. (2007). Case Analysis of Atmospheric Particulate Matter Discharged from Shanxi to Beijing. Journal of the Graduate School of the Chinese Academy of Sciences, 24, 636-640. 